\title{
1076 Effects of age and gender on right ventricular structure and function: a turning point at age fifty
} Mark J Goldman ${ }^{1}$, Dipti Gupta*1, Suzanne White ${ }^{2}$, William Schapiro1, Nora Ngai ${ }^{1}$, Michael Passick ${ }^{1}$, Jing Han ${ }^{1}$, Jie J Cao ${ }^{1}$ and Nathaniel Reichek ${ }^{1}$

Address: ${ }^{1}$ St. Francis Hospital, Roslyn, NY, USA and ${ }^{2}$ Winthrop University Hospital, Mineola, NY, USA

* Corresponding author

from I th $^{\text {th }}$ Annual SCMR Scientific Sessions

Los Angeles, CA, USA. I-3 February 2008

Published: 22 October 2008

Journal of Cardiovascular Magnetic Resonance 2008, I0(Suppl I):A20 I doi:I0.I I86/I532-429X-I0-SI-A20 I

This abstract is available from: http://jcmr-online.com/content/I0/SI/A20I

(c) 2008 Goldman et al; licensee BioMed Central Ltd.

\section{Introduction}

Cardiac magnetic resonance imaging (CMR) using steadystate free precession is the best method currently available for evaluating the right ventricle (RV).

\section{Purpose}

Our objective was to assess effects of age and gender on RV structure and function in a large population of well characterized normal subjects using CMR.

\section{Methods}

We studied 218 (99 male, 119 female) normotensive, non-obese (BMI < 28), non-diabetic volunteers aged 2090 (mean $54 \pm 15$ ) with normal 2-D echocardiograms on a $1.5 \mathrm{~T}$ Siemens Sonata scanner. TrueFISP cine imaging was used to obtain contiguous $8 \mathrm{~mm}$ short axis slices of the entire RV at end-expiration. Volumetric analysis was performed using Medis MASS. RV volume at end-diastole and end-systole and RV mass were determined and indexed to body surface area (EDVi, ESVi, RVMi) including papillary muscles in the cavity volume.

\section{Results}

Males had larger EDVi, ESVi and RVMi than females at all ages $(\mathrm{p}<0.0001)$, while ejection fraction was greater in females (58\% versus 50\%, p < 0.0001). EDVi and ESVi decreased with age in both men and women. Analysis by age decade revealed that EDVi and ESVi begin to fall at 50-59 years of age $(\mathrm{p}<0.0001$ and $\mathrm{p}=0.0003$, respectively). See Figure 1.

\section{Conclusion}

The right ventricle is larger, indexed for body size, in men than in women at all ages, while ejection fraction is higher in women. RV size falls with age, showing an abrupt decrement at age 50 in both men and women. The mechanisms underlying this dramatic change remain to be determined. 


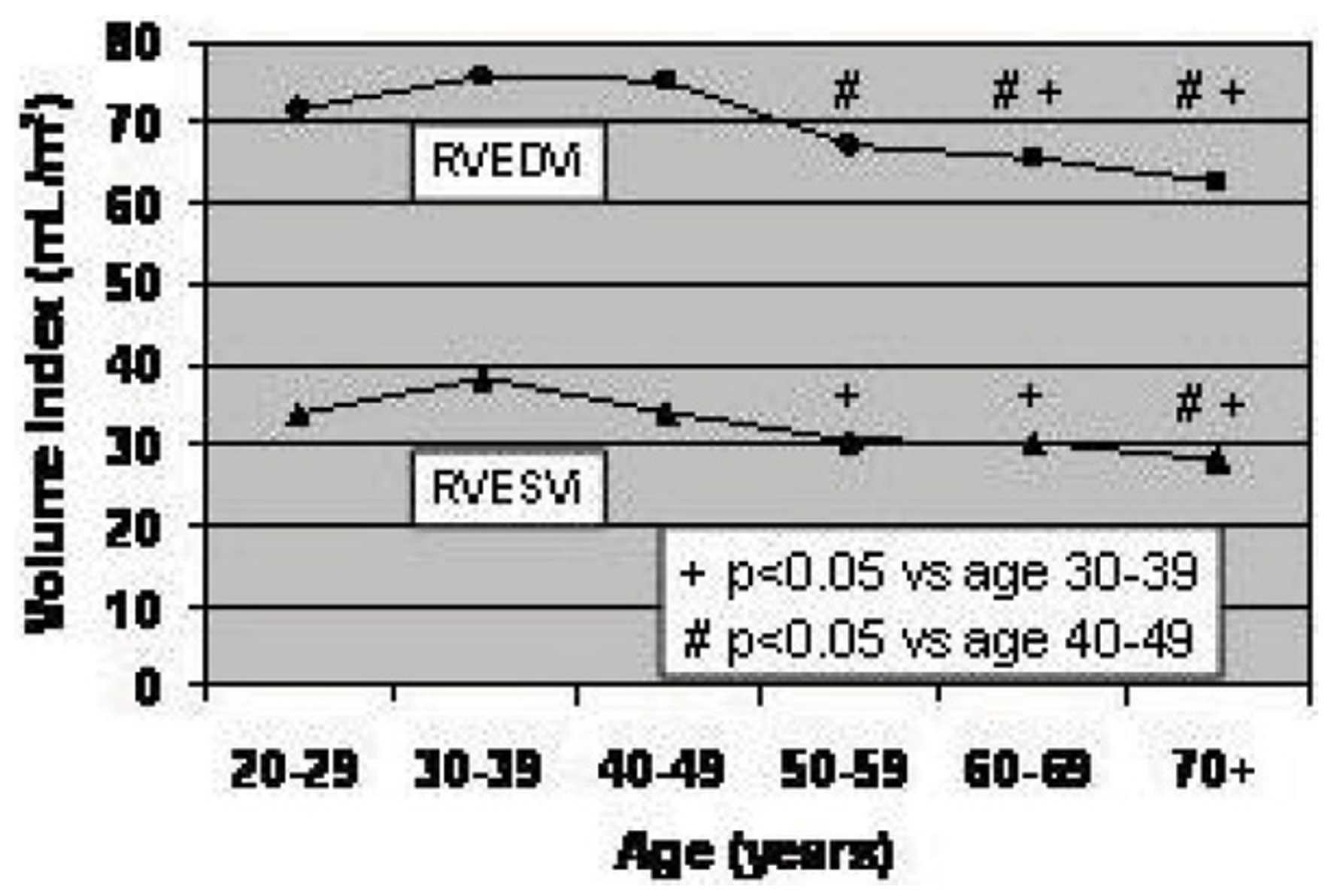

Figure I

\begin{tabular}{|} 
Publish with BioMed Central and every \\
scientist can read your work free of charge \\
"BioMed Central will be the most significant development for \\
disseminating the results of biomedical research in our lifetime." \\
Sir Paul Nurse, Cancer Research UK \\
Your research papers will be: \\
• available free of charge to the entire biomedical community \\
• peer reviewed and published immediately upon acceptance \\
• cited in PubMed and archived on PubMed Central \\
• yours - you keep the copyright \\
Submit your manuscript here: \\
http://www.biomedcentral.com/info/publishing_adv.asp
\end{tabular}

